\title{
Technological catching up, quality of exports and competitiveness: a sectoral perspective
}

\section{Introduction}

In explaining patterns of international specialisation economists commonly refer to the benchmark cases of North-North and North-South trade. In North-North trade frameworks, economies manufacture and export similar products, and market competition is ruled by the ability to introduce a new variety or to step up the quality ladder. In North-South trade cases, high-skill endowed economies manufacture and export innovative products, whereas low-skill endowed countries specialize in low-cost, imitated products. Very little is said about emerging market economies (EMEs) that are placed in between the two cases above. In fact, despite their lower level of per-capita income compared to the rich countries of the North, EMEs generally feature high growth rates of output and a catching-up process on the run; notwithstanding the differences with respect to advanced economies, these economies show a tendency towards a convergence in trade patterns. All this makes EMEs an attractive case study for international economists. Of special interest is the case of the Central and Eastern European countries (CEECs) that have recently joined the European Union (EU). Understanding the evolution of CEECs' structure of trade and export competitiveness is particularly highlighting in the debate on the European enlargement process as a driver of economic convergence. Indeed, economic integration has fostered the exchange in goods and services, business contacts, and so on, and is thus expected to have promoted the dissemination of knowledge, i.e., the mechanism for accelerating the economic catching-up. ${ }^{1}$ The enlargement process is thus likely to have induced an increasing economic similarity between CEECs and the

\footnotetext{
${ }^{1}$ Yet, economic integration per se is not sufficient for a successful catching up; the so-called "advantage of relative backwardness" takes place only in the presence of "absorptive capacity" (Abramovitz 1986), i.e., the availability of technological capabilities, particularly in terms of skilled workers. This factor ultimately determines the ability or inability of any given country to exploit the dynamical gains from trade.
} 
more advanced EU countries, which ought to be reflected in the evolution of trade patterns. A number of contributions in the literature addresses the issue of CEECs' trade structure convergence towards EU's patterns; yet, limited attention has been drawn to the role of the enlargement process as a driver of CEECs' technological catching up and export performance. ${ }^{2}$ With this paper we add to the above strand of literature. by providing a theoretical and empirical contribution to the analysis of the relationship between the evolution of CEECs' competitiveness at the industry-level and the process of technological catching up induced by economic integration with more advanced EU economies. The novelty of our paper is the explanation of sectoral differences in export competitiveness and market shares' growth as the result of a skill endowment-driven specialization that makes high skill-intensive (HS) firms able to benefit by economic integration, catch up technologically with more advanced European foreign firms, and succeed in "quality- dominated" markets.

In view of validating the idea pursued in the paper, we develop a theoretical setup where we explicitly take into account sectoral differences in technological capabilities and skill intensities. This allows us to explain the different features of competitiveness in trade: HS firms face a "nonprice" competition in European markets based on the ability to succeed in the quality upgrading of manufactured products, whereas low-skill (LS) firms face a traditional price competition, fundamentally centred on the ability to preserve a lower labour cost dynamics. Hence, our analysis is set in a dynamical perspective, with a view to explaining market penetration for HS firms as the result of an innovation-driven quality upgrading process. To this end, we first derive analytically export functions where the relative quality content of any product determines its share in importer's expenditure; we then explain the evolution of market shares with firms' ability to improve the exports' relative quality content . In this respect, we differ from Hallak (2006), since we model analytically the technological catching-up fuelled by economic integration as the engine of a

\footnotetext{
${ }^{2}$ Among the most recent contributions on this topic are the works by Cavallaro and Mulino (2008 and 2009a), Caporale et al. (2009).
} 
dynamical process of increasing competitiveness in "quality-dominated" markets. To our knowledge, this aspect is completely new in the literature.

As to the empirical analysis of the paper, we focus on the role of preference for quality in explaining trends in CEECs' exports towards EU partners. We choose to preliminary regress unit value ratio $(U V R)$ changes against several variables measuring domestic and foreign knowledge, that in our theoretical setup drive the process of quality upgrading. In a second step, on the basis of the estimation results that validate econometrically our assumption that the $U V R$ is a good proxy for quality in the case of HS industries, we use the fitted UVR to build a "demand for quality" variable used in the estimation of HS's market shares changes. Our econometric approach differs from Hallak (2010) where per-capita income is used to measure exports' quality content. Indeed, here we are interested in emphasizing the evolution of CEECs' trade patterns and understanding its determinants, and for this purpose the use of a sectoral $U V R$ is more appropriate, given that CEECs' level of per-capita income is lower than EU members', even though the quality content of their advanced products is comparable to EU's.

The paper is organized as follows. Section 2 presents an overview of the literature on product quality and trade; Section 3 develops the basic relationships of the theoretical model, and derives export functions for HS and LS industries. Section 4 analyses the dynamical implications for market penetration of a price- or quality-based competitiveness, and formalizes the role of international knowledge diffusion as driver of a successful competitiveness in "quality-dominated" markets. Sections 5 develops the empirical analysis of the paper with reference to the CEECs. We first provide empirical evidence related to market penetration and price and quality competitiveness, at the industry level, for the period 2000-2007; we then test at the sectoral level the assumption that $U V R$ provides an adequate proxy for quality in trade and finally estimate the role of quality upgrading in HS firms' market shares changes over the period considered. Section 6 draws some final conclusions.

\section{Product quality and trade: a survey of the literature}


This paper contributes to the existing theoretical and empirical literature on the role of product quality in trade, pioneered by Linder (1961). Linder predicted that similar countries would trade more intensely with one other, as they share similar production and consumption patterns. Since firms in the manufacturing sector respond primarily to domestic demand, high-income countries specialize in high-quality goods for the domestic market, and then become exporters of such goods to countries with similar per-capita income.

Although the "Linder hypothesis" encloses both a supply- and a demand-side explanation of the relationship between product quality and trade, research in this area has focused distinctively on the two aspects. As to the production side, some authors point to the relationship between per-capita income and quality production, and find evidence of a strong correlation between export prices and countries' per-capita income, in that richer countries export higher quality goods at higher prices (Hummels and Klenow, 2005). The explanation, as in Murphy and Shleifer (1997) and Schott (2004), is based on factor endowments considerations: capital- and skill-abundant countries exploit their advantage in the production of higher quality goods, that command a relatively higher market price. In the same vein, but in a North-South context, Flam and Helpman (1987) and Stokey (1991) present a quality-based product cycle model where Northern countries that engage in R\&D activity manufacture and export innovative, higher quality products, whereas Southern countries have a comparative advantage in low-cost, labour-intensive productions and export imitated products. As a result, rich countries' endowment-driven comparative advantage in the production of vertically superior varieties brings about differences in per-capita income, which are reflected in the observed international patterns of consumption. As to the demand-side, most contributions investigate the relationship between per-capita income and demand for quality; evidence of wealthier countries consuming high-quality goods in larger proportions than poorer countries is provided by Bils and Klenow (2001), Brooks (2006), Hallak (2006), Verhoogen (2008). The last two authors offer a theoretical foundation of the empirical results based on non-homotheticities in the demand for quality, that makes countries differ in their willingness to pay for vertically superior varieties. 
Despite the numerous empirical validations of the role of quality in trade, the Linder hypothesis as such has found scarce empirical support. Hallak (2010) shows that the above failure is due to the systematic bias induced by the aggregation across sectors. Hallak's theoretical framework includes both quality demand and supply: countries' expenditure shares on different quality products varies with per-capita income, whereas quality supply is assumed to be systematically related to per capita income. The combination of the above demand and supply determinants into a gravitational-type specification leads to the estimation of bilateral trade flows at the sectoral level, where differences in cross-country income per capita represent the Linder term. This turns out to be significant and with the correct sign.

As to the role of quality in trade with specific reference to the CEECs, the contributions in the literature are not numerous. Aturupane et al. (1999) find that trade of similar goods of different quality (vertical intra-industry trade) have been gaining a predominant role in two-way trade between CEECs and richer EU-15, as early as the first half of the 1990s. The authors link the above evolution to inward FDI as well as skill intensity of production and imports of intermediate goods. Subsequent contributions emphasize that CEECs exports' improvement have been due especially to the specialization in up-market, up-quality products. In fact, with reference to a sub-set of these countries, Dullek et al. (2005) show that over the period 1995-2000 the composition of exports towards EU-15 has shifted towards higher-quality segments within industries. Benkovskis et al. (2010) confirm that the above is an on-going process, showing that a large part of the increase in the prices of CEECs' exports towards the EU in the period 1999-2009 results from improving quality, albeit the quality level of CEECs' exports is still lagging behind in comparison with German exports. The link between CEECs' quality upgrading in manufactured products and their competitiveness in EU markets is addressed by Cavallaro and Mulino (2008) where evidence is found of an increased market penetration of CEEC's exports over the period 1995-2005, linked to the increasing role of intra-industry trade and vertical differentiation and a process of specialization 
in higher quality products. The association between CEECs' quality upgrading and their increase of (world) market shares is also highlighted by Fabrizio et al. (2007).

\section{The theoretical model}

We consider an emerging economy that trades with a technologically more advanced foreign country, where we distinguish between HS firms that engage in research activity and manufacture advanced products, and LS firms that manufacture traditional products. As in recent trade theory, the framework considered is that of a semi-small open economy, where imported goods are purchased at given world prices, and producers of final goods compete monopolistically in international markets, given that traded products substitute imperfectly for each other in households' demand. We assume no tariffs, transportation costs or other trade barriers, and that all factors of production are immobile.

\subsection{The supply side}

We distinguish between two types of final products: advanced and traditional. The $N$ differentiated advanced goods - indexed by $n$, with $n=1, \ldots, i, \ldots, N$ - are manufactured with highskilled labour and an aggregate of advanced intermediate inputs that embody quality improvements stemming from research activity. As in new-Schumpeterian quality ladder models, firms that manufacture innovative intermediates engage in research activity in order to create blueprints. When they succeed in up-front research they have the ability to gain industry leadership for the innovative product. We characterize the typical HS firm that manufactures the advanced final product, $Y_{i}$, by the following technology:

$$
Y_{i}=F_{i} H_{i}^{\alpha} A_{i}^{1-\alpha}
$$


where $H_{i}$ is employment of high-skilled labour, $A_{i}$ the amount of intermediates in the manufacture of the final product by firm $i$ and $F_{i}$ is an arbitrary constant reflecting the choice of units. ${ }^{3}$ We follow Grossman and Helpman (1991) in modeling the intermediate goods sector and assume that firms employ a fixed assortment of vertically differentiated intermediate inputs, indicated by the following index:

$$
\log A=\int_{0}^{1} \log \left(\sum_{z} q_{z \kappa} Z_{z \kappa}\right) d z
$$

where $Z_{z \kappa}$ represents the component $z$, of the $\kappa^{\text {th }}$ generation, in the index $A$, whose quality is $q_{z \kappa}$. To simplify we let the innovation process be such that each new intermediate provides $\gamma$ additional services with respect to the good of the previous generation, that is $q_{z \kappa}=\gamma q_{z(\kappa-1)}$, with $\gamma>1$.

The research sector is portrayed as in the patent-race literature. Firms target their research effort at the quality upgrading of any leading-edge production process; they issue equity to finance the $R \& D$ race and use a constant-return-to-scale technology where skilled labour is the only input. Any firm that engages $H_{R}$ labour resources in industry $z$ at time $t$ is able to produce the new good with probability $l_{H} \cdot{ }^{4}$ The probability of gaining success in lab activity is proportional to the resources devoted: to achieve a research intensity of $l_{H}$, it is necessary to invest $H_{R} \equiv \ell_{H} l_{H}$ units of labour services per unit of time, where $\frac{1}{\ell_{H}}$ is the productivity of labour in research. Firms will invest labour in research activity up to the amount for which the cost of R\&D activity equals the expected revenues.

\footnotetext{
${ }^{3}$ To save on notation we have omitted the time index.

${ }^{4}$ The arrival of research successes is guided by a Poisson process, with $l$ denoting the parameter of the density function. Although the arrival of research successes among firms is guided by independent Poisson processes, by the law of large numbers, the process of technological advance at the aggregate level is smooth and non-random. See Grossman and Helpman (1991).
} 
As to the manufacture of advanced intermediates $A$, firms use a constant-return-to-scale technology that employs only labour. Given monopolistic competition and limit pricing outcome, all intermediates bear the same price. Since better quality inputs are more productive, in that they allow to produce a higher-quality final good, producers of final goods buy only state-of-the-art varieties. Given that all demanded components $Z_{z}$ are employed in equal quantities, the aggregate intermediate $A$ can be expressed as $A=q Z$ where $Z$ denotes the aggregate volume of intermediates and $q$ is an index of the productivity of intermediates which is proportional to the total "number" of R\&D successes. Hence, the resulting quality content embodied in advanced final products reflects the country's state of knowledge, at a given time $t$.

In addition, in the economy there are $M$ differentiated traditional products - indexed by $m$, with $m=1, \ldots, j, \ldots, M$ - that are manufactured with low-skilled workers. The representative LS firm that manufactures a traditional product $j$ is characterized by the following technology:

$$
Y_{j}=F_{j}\left(L_{j} B\right)^{\beta}
$$

where $F_{j}$ is an arbitrary constant reflecting the choice of units, $L_{j}$ is employment of low-skilled labour and $B$ denotes a learning-by-doing process that increases workers' productivity. In particular, we assume learning by doing to be linked to the stock of knowledge accumulated in the economy. The idea is that the innovative activity taking place in the HS industry leads to the spread of general knowledge that may be partly seized by LS firms. Since domestic knowledge is embodied in advanced intermediate inputs, we assume the learning-by-doing process to be linked to the production of these intermediates. At the same time, economic integration with more advanced economies favours the diffusion of foreign knowledge, in particular through the channel of foreign direct investments. We thus posit $B=\mu\left(A^{\varepsilon} A^{*(1-\varepsilon)}\right)$, with $\mu^{\prime}>0, \quad \mu^{\prime \prime}<0$, where $\mu$ is a function denoting the LS firm's ability to absorb externally generated knowledge present in the public domain. We assume that the contribution of the accumulated knowledge to LS firms' productivity growth exhibits decreasing returns due to the difficulties of learning in the presence of growing 
complexity of advanced intermediates and sectoral specificities. Parameters $\varepsilon$ and $(1-\varepsilon)$ are the weights of the domestic and foreign sources of learning, that is, $A$ and $A^{*}$, respectively.

\subsection{The demand side}

Preferences of any domestic household $h$ are described by the following intertemporal utility function

$$
U_{\tau}^{h}=\int_{\tau}^{\infty} e^{-\rho(t-\tau)} \log u_{t}^{h} d t
$$

where $\rho$ represents the subjective discount rate and $u_{t}^{h}$ the following instantaneous utility function:

$$
u_{t}^{h}=\left(C_{A}^{h}\right)^{\alpha}\left(C_{T}^{h}\right)^{1-\alpha}
$$

where

$$
\begin{aligned}
& C_{A}^{h}=\left\{\sum_{n}\left[\sum_{\kappa}\left(q_{H(\kappa)}\right)^{\omega} C_{H(\kappa, n)}\right]^{\sigma_{A}}+\sum_{n^{*}}\left[\sum_{\kappa^{*}}\left(q_{F\left(\kappa^{*}\right)}\right)^{\omega} C_{F\left(\kappa^{*}, n^{*}\right)}\right]^{\sigma_{A}}\right\}^{\frac{1}{\sigma_{A}}} \\
& C_{T}^{h}=\left(M+M^{*}\right)^{1-\sigma_{T}}\left(\sum_{m}\left(C_{H m}\right)^{\sigma_{T}}+\sum_{m^{*}}\left(C_{F m^{*}}\right)^{\sigma_{T}}\right)^{\frac{1}{\sigma_{T}}}
\end{aligned}
$$

In equation (5) $C_{A}^{h}$ denotes consumption of advanced goods and $C_{T}^{h}$ of traditional products. Equation (6) states that $C_{A}^{h}$ is a function of the level of consumption of each domestic advanced good $n, C_{H(\kappa, n)}$, and of each foreign advanced good $n^{*}, C_{F\left(\kappa^{*}, n^{*}\right)}$, where $n^{*}=1, \ldots, i^{*}, \ldots, N^{*}$. Each distinct advanced product may be manufactured in an infinite number of ways, corresponding to a different vintage $\kappa$; different vintages of a given product substitute perfectly for one other, once the appropriate adjustment is made for the different quality levels; $q_{H(\kappa)}$ is the quality level embodied in vintage $\kappa$ of any domestic advanced good, and analogously $q_{F\left(\kappa^{*}\right)}$ is the quality level embodied in vintage $\kappa^{*}$ of any foreign high-tech good. Equations (5)-(7) state that each consumer maximizes static utility by devoting a fraction $\alpha$ of her expenditure to the set of advanced goods and the remaining fraction to the set of traditional goods; within the 
advanced set, preferences over home and foreign products are modelled according to a qualityadjusted CES function, so that the whole set of the $N$ domestic and $N^{*}$ foreign varieties, are demanded. Thus, once the distribution of expenditure across advanced and traditional goods has been set, the consumer first selects among generations of any available domestic and foreign product, $n$ and $n^{*}$, the brand of vintage $\hat{\kappa}$ and $\hat{\kappa}^{*}$ that carries the lowest quality-adjusted price; she then allocates expenditure among the whole set of $N+N^{*}$ products according to the relative prices and relative quality content. ${ }^{5}$ The functional form (6) implies a constant elasticity of substitution between advanced goods, given that $\sigma_{A}=\frac{\theta_{A}-1}{\theta_{A}}$, where $\theta_{A}$ is the constant elasticity of substitution between each pair of advanced goods. The weight of each good in the consumption of the advanced bundle is proportional to its quality level $q_{H(\kappa)}$ or $q_{F\left(\kappa^{*}\right)} ; \omega$ is a positive parameter that measures the household's intensity of preference for quality, as in Hallak (2006), Crinò and Epifani (2010).

As to traditional goods, $C_{T}^{h}$ is a function of the level of consumption of each traditional domestic good $m, C_{H m}$, and each foreign good $m^{*}, C_{F m^{*}}$, where $m^{*}=1, \ldots, j^{*}, \ldots, M^{*}$. Equation (7) assumes a constant elasticity of substitution between traditional goods, given that $\sigma_{T}=\frac{\theta_{T}-1}{\theta_{T}}$, where $\theta_{T}$ is the constant elasticity of substitution between each pair of traditional goods; moreover, all traditional goods enter $C_{T}^{h}$ symmetrically.

\footnotetext{
${ }^{5}$ Once the above two static maximization problems have been solved, the optimal allocation of expenditure across time is readily obtained as the solution to a standard intertemporal maximization problem. The occurrence of a two-stage static optimization problem stems from the presence of both a vertical and a horizontal dimension in consumer's preferences. See Grossman and Helpman (1991).
} 
Optimal allocation of expenditure across the $N$ domestic and $N^{*}$ foreign (state-of-the-art) products implies the following demand function for domestic advanced consumption good $i, C_{H i}$, with quality $q_{H}$ and price $P_{H i}$ (see Appendix for details):

$$
C_{H i}^{h}=\left(\frac{P_{H i}}{P^{A}}\right)^{-\theta_{A}}\left(Q_{H}\right)^{\left(\theta_{A}-1\right)} \frac{\alpha E^{h}}{P^{A}}
$$

where $\alpha E^{h}$ denotes the representative consumer's share of expenditure over advanced goods, $P^{A}$ the advanced goods price index consistent with the quality-adjusted CES type of preferences, and where $Q_{H} \equiv \frac{\left(q_{H}\right)^{\omega}}{\sum_{n=1}^{N}\left(q_{H}\right)^{\omega}+\sum_{n^{*}}^{N^{*}}\left(q_{F}\right)^{\omega^{*}}}$. Equation (8) shows the role of the relative quality content of goods in the structure of demand for advanced products. In fact, $Q_{H}$ is a "distribution" parameter in that it gives the share of the (advanced goods) expenditure devoted to domestic good $i$, for given relative prices.

Analogously, with respect to the demand for any domestic traditional good $j$, we obtain a demand function of the form:

$$
C_{H j}^{h}=\left(\frac{P_{H j}}{P^{T}}\right)^{-\theta_{T}} \frac{(1-\alpha) E^{h}}{\left(M+M^{*}\right) P^{T}}
$$

where $(1-\alpha) E^{h}$ represents the representative consumer's share of expenditure over traditional goods and $P^{T}$ is the traditional goods price index consistent with the CES-type of preferences.

Comparison of equations (8) and (9) makes evident the implications of the inclusion of the quality dimension in consumers' preferences. To see this clearly, we re-express relative demand between any domestic and foreign advanced product and between any domestic and foreign traditional product, respectively, as:

$$
\frac{C_{H i}^{h}}{C_{F i^{*}}^{h}}=\left(\frac{P_{H i}}{P_{F i^{*}}}\right)^{-\theta_{A}}\left(\frac{q_{H}}{q_{F}}\right)^{\omega\left(\theta_{A}-1\right)} \quad \frac{C_{H j}^{h}}{C_{F j^{*}}^{h}}=\left(\frac{P_{H j}}{P_{F j^{*}}}\right)^{-\theta_{T}}
$$


The above equations show that for given relative prices and elasticity of substitution, relative demand for advanced goods depends on products' quality ratio; moreover the higher is the intensity of quality preference, $\omega$, the more relative quality matters. Our result is in line with Hallak (2006) that argues that high-quality products have easy access to rich markets where high-income consumers are more quality oriented. On the contrary, relative demand for traditional products depends only on relative prices, for any given elasticity of substitution, just as in traditional CEStype preferences.

We now focus on the emerging country's exports, that is, on foreign demand for advanced and traditional products. To this end we let the structure of foreign preferences to be symmetric to the one given in equation (5) so that, at each time $t$, the representative foreign household's demand for any (domestic) advanced product $i$ is given by substituting her intensity of preference for quality, $\omega^{*}$, and her expenditure, $\alpha E^{h^{*}}$. Same applies to non-residents' demand for any domestic traditional product $j$.

At each time $t$, exports of high-tech domestic goods are obtained by aggregating the individual demand functions for the whole set of $N$ domestic advanced goods:

$$
X^{A}=\sum_{h^{*}} \sum_{n} P_{H n}\left(\frac{P_{H n}}{P^{A}}\right)^{-\theta_{A}} Q_{H}^{\left(\theta_{A}-1\right)} \frac{\alpha E^{h^{*}}}{P^{A}}
$$

Correspondingly, exports of traditional domestic goods are given by:

$$
X^{T}=\sum_{h^{*}} \sum_{m} P_{H m}\left(\frac{P_{H m}}{P^{T}}\right)^{-\theta_{T}} \frac{(1-\alpha) E^{h^{*}}}{\left(M+M^{*}\right) P^{T}}
$$

\section{Market penetration and quality dynamics}

The focus now is on the dynamical implications of the different kind of competitiveness faced by HS and LS firms, as resulting from the two functional forms obtained above - equations (10) and (11). To see this we look at the evolution of HS and LS market shares. We define the 
market share of domestic HS firms as the ratio of non-residents' imports, $X^{A}$, to non-residents' purchases of advanced products manufactured in their own country, $G^{A}$. Given the monopolistic competition setting, where all domestic HS firms have identical technology and face the same demand, we have a symmetric equilibrium, ${ }^{6}$ with all domestic firms of the advanced industries fixing the same price, $P_{H i}=P_{H}^{A}$. Thus, we may reformulate equation (10) as

$$
X^{A}=N\left(\frac{P_{H}^{A}}{P^{A}}\right)^{1-\theta_{A}} Q_{H}^{\left(\theta_{A}-1\right)} \alpha E^{*}
$$

where, now, $\alpha E^{*}$ denotes aggregate foreign expenditure over the EME's advanced products, expressed in terms of the domestic currency. In turn, by assuming $P_{F i^{*}}=P_{F}^{A}$, the equation for nonresidents' purchases of advanced products manufactured in their own country is

$$
G^{A}=N^{*}\left(\frac{P_{F}^{A}}{P^{A}}\right)^{1-\theta_{A}} Q_{F}^{\left(\theta_{A}-1\right)} \alpha E^{*}
$$

The evolution of high-tech products' market shares is then readily derived by taking the logarithmic differentiation with respect to time of the ratio of equations (12) and (13):

$$
\tilde{X}^{A}-\tilde{G}^{A}=\left(1-\theta_{A}\right)\left[\left(\tilde{P}_{H}^{A}-\tilde{P}_{F}^{A}\right)-\omega^{*}\left(\tilde{q}_{H}-\tilde{q}_{F}\right)\right]
$$

It appears clearly that market penetration abroad depends on the evolution of both the pure price term and the quality differential term; the weight of the latter depends on the intensity of foreign consumers' preference for quality. The implications for competitiveness and export orientation are twofold: firms that well-perform in "quality dominated markets" are able to expand along the "intensive margin", that is, to gain market shares even at constant or increasing relative prices. Moreover, were the intensity of quality demand related to consumers' income as stated in Hallak (2006), high-tech innovative goods would find easier markets in high-income countries.

\footnotetext{
${ }^{6}$ The authors develop the general equilibrium analysis for a similar model in a previous paper (Cavallaro and Mulino, 2009); interested readers may refer to that paper for details.
} 
As regards LS industries, the evolution of market shares is obtained by restating equation

(11) for non-residents' imports as

$$
X^{T}=\frac{M}{M+M^{*}}\left(\frac{P_{H}^{T}}{P^{T}}\right)^{1-\theta_{T}}(1-\alpha) E^{*}
$$

where $P_{H j}=P_{H}^{T}$ and where $(1-\alpha) E^{*}$ denotes aggregate foreign expenditure over the EME's traditional products, expressed in terms of the domestic currency. Given $P_{F j^{*}}=P_{F}^{T}$, the equation for non-residents' purchases of traditional products manufactured in their own country is

$$
G^{T}=\frac{M^{*}}{M+M^{*}}\left(\frac{P_{F}^{T}}{P^{T}}\right)^{1-\theta_{T}}(1-\alpha) E^{*}
$$

so that the evolution of market shares for low-tech products is

$$
\tilde{X}^{T}-\tilde{G}^{T}=\left(1-\theta_{T}\right)\left(\tilde{P}_{H}^{T}-\tilde{P}_{F}^{T}\right)
$$

It appears that firms of LS industries can only engage in a traditional "price competition" in order to penetrate foreign markets. In this respect, the learning-by-doing technology brings about labour productivity increases that loosen the pressure on wages which is required to keep market shares constant. It turns out that the innovation activity in the advanced sector has positive external effects on the traditional firms too, and hence the determinants of the pace of innovation in the advanced sector of the economy are important for the overall evolution of the country's performance in international markets.

As standard in neo-Schumpeterian growth models, we assume that firms step up the quality ladder thanks to innovations resulting from the devotion of labour resources to research activity. In our analysis we consider international spillovers as important factors in the building up of an emerging economy's stock of knowledge, and hence take as relevant for the process of quality upgrading a concept of knowledge capital that includes both domestic and foreign know-how. ${ }^{7}$

\footnotetext{
${ }^{7}$ We consider international R\&D spillovers, FDI, business contacts, as the means that may convey technology transfers within our theoretical framework. As suggested in Keller (2004), the above are among the strongest form of knowledge
} 
Some contributions in the literature ${ }^{8}$ include international knowledge spillovers in models where innovation activity is conceived as a horizontal process of increasing varieties. Here, we focus on a vertical innovation process and assume the following technology for quality upgrading (see Cavallaro and Mulino, 2008):

$$
\frac{d q_{H}}{d t}=K_{H} \frac{H_{R}}{\ell_{H}} \log \gamma
$$

where $K_{H}$ is the economy's overall stock of knowledge capital, at a given time $t$, specified as $K_{H}=K\left[q_{H}, q_{F}\right]$. Equation (18) states that the productivity of labor resources in research, $\frac{1}{\ell_{H}}$, is increased by the stock of knowledge capital $K_{H}$, as standard in innovation-driven endogenous growth models with international knowledge spillovers. We take $K(\cdot)$ to be increasing in both arguments and homogeneous of degree one. The latter assumption allows us to define the “intensive" function $\Psi \equiv K\left[1,\left(q_{F} / q_{H}\right)\right]$ such that $K_{H}=q_{H} \Psi\left(q_{F} / q_{H}\right)$. The function $\Psi($.$) reflects$ the existence of international spillovers. The case of no international spillovers is one where

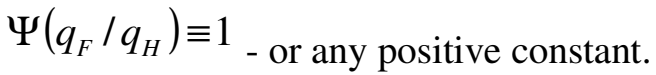

Rearranging, we can express the growth rate of quality in the research sector as:

$$
\tilde{q}_{H}=\Psi\left(\frac{q_{H}}{q_{F}}\right)^{-1} \frac{H_{R}}{\ell_{H}} \log \gamma
$$

where $\left(\frac{q_{H}}{q_{F}}\right)$ is a measure of the knowledge gap between the two countries. Equation (19) emphasizes the convergence pattern of integrated economies: the growth of quality over time is positively related to the technological disadvantage of the laggard country, given its capacity to

diffusion. Intermediate goods, which also are emphasized in some contributions in the literature (See Maggi et al., 2009, among the others) have to be excluded in our analysis, being non-traded by assumption).

${ }^{8}$ See, among the others, Grossman and Helpman (1991), Smulders (2004), Leon-Ledesma (2005). 
benefit by the international dissemination of knowledge, as represented by the specific functional form adopted for $\Psi(\cdot)$.

In conclusion, economic integration with more advanced countries exerts a twofold positive effect: on one side, it speeds up the technological catching up and exports' quality upgrading; on the other side, it provides easy access to rich markets where high-income consumers are more quality oriented. The model predicts that the positive impulses to the modern, dynamic industries are also indirectly beneficial to the traditional sectors of the economy.

\section{Export quality, technology and market penetration of CEECs: econometric analysis}

In this section we estimate for CEECs equation (14) of the theoretical model, ${ }^{9}$ which states that the growth rate of market shares depends on a pure price term and a "demand for quality" term.

Given the focus on the role of product quality in trade, our preliminary concern is the appropriate measure of quality to be used in the econometric estimation. The empirical literature suggests two alternative possibilities: the use of either a total factor productivity measure (Verhoogen, 2008, Crinò and Epifani, 2010), or indicators based on export unit values (Greenaway et al., 1995, Fontagné and Freudenberg, 1997, Schott, 2004, Hummels and Klenow, 2005, Hallak and Schott, 2011). In our analysis we follow the latter approach, and build a unit value ratio to be used as a proxy for relative quality in the estimation of equation (14). We validate its use by running a preliminary regression in order to test the influence on $U V R$ changes of several technological variables lying behind the accumulation of knowledge capital, that in our analysis are at the root of the process of quality upgrading. On the basis of the results obtained that confirm that for HS industries $U V R$ is a good proxy for quality, we use the fitted values of $U V R$ to build the

\footnotetext{
${ }^{9}$ For the CEECs we only consider the Czech Republic, Hungary, Poland and Slovenia, because of missing data on technological variables for the other countries, whereas among the EU-15 countries we do not consider Luxembourg, owing to its small dimension.
} 
"demand for quality" term in our estimation of market shares changes between 2000 and 2007. The choice of performing regressions on the overall changes instead of using panel data techniques is due to the high number of missing sectoral data, especially for domestic R\&D expenditure. Given our focus on basic long-term trends we leave aside data referring to 2008 onward for the adverse impact of the recent global financial crisis on output growth and the volumes of trade, as well as other important variables considered in our estimation, such as FDI flows and R\&D expenditure.

\subsection{Data and descriptive evidence}

Trade data are taken from Eurostat COMEXT database, which reports values and quantities for industrial products according to the 8-digit level Combined Nomenclature classification (CN8). The breakdown of exports according to skill intensities is based on the NACE (DA-DN) classification that divides manufactured products into 14 industries. Following a standard classification, we consider as HS industries Chemical Products (DG), Machinery and Equipments (DK), Electrical and Optical Equipments (DL) and Transport Equipments (DM). In addition, some studies (Esposito and Stehrer 2009; Landesmann et al. 2009) suggest that CEECs are relatively skill intensive in Paper, Printing and Publishing (DE) as well as Coke and Refined Petroleum Products (DF) industries, whereas skill-biased technical change has been strongly concentrated in skillintensive industries (Esposito and Stehrer 2009). Accordingly, we also include these industries among the HS. All other industries are classified as LS. As common in most empirical contributions, we define the market share of a given industry as the ratio of exports of the reporter country to the total imports of the partner country from the EU-25 area. ${ }^{10}$ We consider only intraEU trade because of the strong linkages in manufacturing processes and the relevance of trade relationship for CEECs. We obtain trade at constant values by evaluating 2000 quantities at 2007 unit values; we then aggregate them into HS and LS industries.

\footnotetext{
${ }^{10}$ We exclude from the sample Cyprus and Malta due to their small size.
} 
Consistently with our definition of market shares, the $U V R$ is the ratio between reporter $k$ export unit values towards partner $j$ and total intra-EU import unit values of the partner, for each type of industry $i\left(U V R_{i}^{k, j}\right)$, and is built as a weighted average of the relative unit values at product level, ${ }^{11}$ where the weights are the shares of each product's export in the industry's total exports. ${ }^{12}$ We dropped observations belonging to the upper and lower 5\% of the distribution, since large differences in unit values point to a composition effect within product categories, that is, to the presence of heterogeneous goods; in this case, it is likely that price differences are not associated with differences in the goods' quality content. In addition, we consider that aggregate $U V R$ of a fixed-products dataset can change either because of changes in the relative prices of products ("within" product changes), or because of the changing composition of the basket ("between" products changes), with the latter denoting changes in the export specialisation towards a different composition of the basket. Therefore, in order to isolate "pure" relative price changes, we purge composition effects by computing the within-product component of the $U V R$ growth (UVRw, henceforth) by weighting product-level relative prices with the initial export volume:

$U V R w_{s, t}^{k, v}=\frac{\sum_{r} p_{r, t}^{k, v} * \eta_{r}^{k, v}}{\sum_{r} p_{r, 2000}^{k, v} * \eta_{r}^{k, v}} / \frac{\sum_{r} p_{r, t}{ }^{E U, v} * \eta_{r}^{E U, v}}{\sum_{r} p_{r, 2000}^{E U, v} * \eta_{r}^{E U, v}} \quad$ with $\quad \eta_{r}=\frac{p_{r, 2000} y_{r, 2000}}{\sum_{r} p_{r, 2000} y_{r, 2000}}$

where $t$ is the time period, $p$ is the price of the generic product $r$ belonging to industry $s, \eta$ is the share of each product in total industry's export value and the superscripts indicate the origin $(k, E U)$ and destination $(v)$ markets.

\footnotetext{
${ }^{11}$ We consider narrowly defined product categories at the CN8 level.

${ }^{12}$ The $U V R$ we build is analogous to the ones present in Greenaway et al. (1995) and Fontagné and Freudenberg (1997), among the others. Alternative measures of product quality based on export unit values have been operationalized in the literature. For instance, Hallak and Schott (2011) decompose observed export prices into quality and pure price components, thanks to the use of information on consumers' evaluation of products inferred from countries' trade balances.
} 
As to the variables related to the accumulation of knowledge capital, we consider R\&D expenditure for both CEECs4 and EU. Data are from Eurostat ${ }^{13}$ and OECD, respectively. We then use FDI data from the WIIW database on Foreign Direct Investments, that includes FDI stocks and flows in each industry for Central and Eastern European countries. As to the variables referring to the demand side, we include a "Linder term"" (QDEM) where changes in quality, proxied by changes in $U V R w$, interact with foreign per-capita GDP in order to capture the intensity of preference for quality. Per-capita GDP is from Eurostat.

In Table 1 we present data on $U V R$, market shares and price determinants, i.e., unit labour costs and innovation costs, over the period 2000-2007. These trends highlight the different features of competitiveness in trade for HS and LS industries. In particular, the figures related to the $U V R$, $U V R w$ and market shares point to a striking different performance between the two kind of industries. It is worth noticing the sizeable increase in market shares for HS industries, slightly below $75 \%$, matched by the positive change in both $U V R$ indexes which is stronger for the within products component (29\%). Albeit starting from a lower level, at the end of the period HS industries recorded higher market shares than LS industries. The fact that firms in HS industries gain market shares at increasing $U V R \mathrm{~s}$ is an evidence of the ability to penetrate foreign markets not so much by reducing prices as by innovating. This points to an innovation-driven successful competition in "quality dominated" markets (Aiginger 1997; Cavallaro and Mulino 2008, 2009a). On the other hand, firms in LS industries record a modest $16 \%$ increase in their market shares, associated with approximately the same price changes.

Table 1 - Unit value ratios, market shares, price determinants: levels and growth rates, CEECs-4

\begin{tabular}{|l|r|r|r|r|r|r|}
\hline & \multicolumn{3}{|c|}{ High-skill industries } & \multicolumn{3}{c|}{ Low-skill industries } \\
\hline & 2000 & 2007 & growth & 2000 & 2007 & growth \\
\hline
\end{tabular}

\footnotetext{
${ }^{13}$ We filled missing values of R\&D expenditure by imputing the average value calculated for high-tech and traditional industries separately.

${ }^{14}$ In Linder (1961) the demand for high-quality goods depends on the consumer's level of income.
} 


\begin{tabular}{|c|c|c|c|c|c|c|}
\hline & & & rate & & & rate \\
\hline $\mathrm{UVR}^{*}$ & 1.04 & 1.20 & $15 \%$ & 0.95 & 1.07 & $13 \%$ \\
\hline $\mathrm{UVRw}^{*}$ & 1.04 & 1.34 & $29 \%$ & 0.95 & 1.09 & $15 \%$ \\
\hline Market shares $^{*}$ & 2.15 & 3.74 & $74 \%$ & 2.89 & 3.35 & $16 \%$ \\
\hline Wages (annual) $(€)^{* * *}$ & 5972 & 7848 & $31 \%$ & 4548 & 6033 & $33 \%$ \\
\hline Lab Prod. $(€)^{* * *}$ & 57204 & 94609 & $65 \%$ & 35808 & 57699 & $61 \%$ \\
\hline Real R\&D (mn€) & 730 & 1157 & $58 \%$ & 252 & 196 & $-22 \%$ \\
\hline Real FDI (mn€) & 15339 & 37103 & $142 \%$ & 14390 & 30193 & $110 \%$ \\
\hline
\end{tabular}

Sources: ${ }^{*}$ Own elaboration on COMEXT data; ${ }^{* *}$ WIIW Industrial database on Eastern Europe; ${ }^{* * *}$ Eurostat; ${ }^{* * * *}$ WIIW Foreign Direct Investment Database.

Wages, productivity, R\&D and market shares are expressed in constant (2000) prices.

Table 1 shows the sizeable increases in wages both in HS and LS industries, coupled with a remarkable favourable evolution of labour productivity; overall, throughout the period considered, CEECs-4 exports wellperform in terms of traditional price competitiveness. As to innovation costs, R\&D expenditure records a noticeable growth in HS industries, and a sizeable fall in traditional industries. In addition, the Table also reports data on the growth rate of inward FDI for both types of industries. As known, this variable acts as a technological vehicle for domestic innovation activity, by means of both "pure" knowledge spillovers and spillovers passing through vertical and horizontal linkages (van Pottelsberghe and Lichtenberg 2001, Keller 2004). The Table shows a faster increase for HS industries than for LS industries. Summing up, data point to a sound evidence of increasing competitiveness in EU markets for CEECs HS industries. In addition, data provide a clear indication that domestic and foreign technology have played a role in fostering export penetration, particularly for HS industries.

\subsection{The effect of domestic and foreign technology on export unit values}

The first estimation aims at capturing the part of the $U V R w$ change due to quality upgrading in HS industries. Following equation (19) we assume that this process is positively influenced by both domestic and foreign knowledge.

Among the regressors, we include the initial value of the relative price, in order to test the effect of the initial quality gap: according to equation (19) of the theoretical model, a country's 
relative technological disadvantage can be a positive determinant of a catching-up process among integrated economies. As to technological variables, domestic knowledge is proxied by the domestic sectoral $\mathrm{R} \& \mathrm{D}$ expenditure $(R D)$, whereas foreign knowledge is accounted for by considering the stock of inward FDI and foreign R\&D expenditure. Our assumption that knowledge spillover effects are fostered by the absorptive capacity of the exporting industry is tested by including an interaction term between inward $F D I$ and domestic $R D$ : the expected sign of the coefficient of this interaction term is positive. In addition, we interact inward FDI with R\&D expenditure of the partner country, as in Léon-Ledesma (2005), in order to take into account the FDI technological content; the expected influence of the latter interaction term is positive, too.

The resulting equation is the following:

$$
\begin{aligned}
& \Delta \ln U V R w_{s}{ }^{k, v}=\beta_{0}+\beta_{1} \ln U V R w_{s}{ }^{k, v}+\beta_{2} \ln F D I_{s}{ }^{k}+\beta_{3} \ln R D_{s}{ }^{k}+\beta_{4} \ln F D I_{s}{ }^{k} * \ln R D_{s}{ }^{k}+ \\
& +\beta_{5} \ln F D I_{s}{ }^{k} * \ln R D^{v}+\beta_{6} \ln R D^{v}+\sum_{s} \gamma_{s}+\sum_{k} \gamma_{k}+\varepsilon_{s, v}
\end{aligned}
$$

where subscript $s$ refers to the industry while superscripts $k$ and $v$ refer to the reporter and partner countries, respectively. We estimate the above equation by carrying out both OLS and Instrumental Variables regressions on the overall changes between 2000 and 2007. The use of the IV estimator is justified by measurement errors and the possibility of a mean-reversion bias arising from symmetric shocks specific to the initial year and from sectoral asymmetric shocks, that would affect the coefficient of the initial $U V R w$. In order to address this problem we run IV estimates using the average manufacturing unit value ratio of 1999 as instrument. We include sector- and reporterspecific dummies $\left(\gamma_{s}\right.$ and $\left.\gamma_{k}\right)$ while partner-specific fixed effects are not included as they are jointly not significant and cause multicollinearity. Obviously, the evolution of relative prices depends also on traditional cost determinants; consequently, we run the above estimation adding the growth rate of real wages and labour productivity. However, the results are not affected by the additional variables, since most of their effects are captured by the reporter- and sector-specific 
dummies. $^{15}$ The results are presented in Table 2. As a control, we estimate equation (21) also for the sub-sample of LS industries where, according to our model, quality plays no role, so that changes in relative prices only reflect changes in unit labour costs.

By looking at Table 2, it appears that the instrument works fine, and both the weak identification and under identification tests are rejected. With reference to IV estimates for HS industries, from column (3) we see that the stock of inward FDI is not significant even after controlling for both domestic and foreign R\&D. Similarly, the latter two variables do not exert a significant impact either. On the contrary, when we add the interaction terms the coefficient for the inward FDI stock (column (4)) turns significant at $1 \%$ level and with the expected positive sign. In addition, both the interaction terms are positive and significant. The above result confirms the importance of CEECs-4 absorptive capacity for the effective ability to exploit foreign know how. The positive sign of the interaction term between FDI and the partner's R\&D suggests that spillovers arising from the stock of foreign technology through inward FDI are positively correlated with the partner's research activity. Overall, $U V R w$ changes respond positively to technological variables, thus validating the hypothesis that changes in product quality are adequately proxied by changes in the $U V R w$. Finally, the OLS estimates in columns (1) and (2) do no differ from the corresponding IV ones, indicating that the endogeneity problem does not affect the results.

Turning to LS industries (columns (5) to (8)), we see that none of the regressors exerts a positive and significant impact on the "within" relative unit value, and this confirms that price changes are not systematically related to innovation costs in these industries. The only significant variables are the initial relative price and the stock of inward FDI, both with a negative sign. The negative sign of inward FDI is explainable in terms of the unit-cost reduction effect of this investment activity, a result in line with the theoretical assumption of learning-by-doing driven productivity gains in these industries. Overall, the results obtained for LS industries validate the assumption of market penetration based on a traditional price competition.

\footnotetext{
${ }^{15}$ The results are available upon request.
} 
Table 2 - Technological determinants of "within" relative prices changes.

\begin{tabular}{|c|c|c|c|c|c|c|c|c|}
\hline & \multicolumn{4}{|c|}{ High-skill industries } & \multicolumn{4}{|c|}{ Low-skill industries } \\
\hline & OLS & OLS & IV & IV & OLS & OLS & IV & IV \\
\hline \multirow[t]{2}{*}{$\operatorname{lnUVRw}_{s}{ }^{k, v}$} & $-0.727^{* * *}$ & $-0.738 * * *$ & $-0.785^{\star \star *}$ & $-0.768^{\star \star *}$ & $-0.832 * * *$ & $-0.828 * * *$ & $-0.695^{\star * *}$ & $-0.710^{\star * *}$ \\
\hline & {$[0.094]$} & [0.092] & {$[0.120]$} & {$[0.117]$} & {$[0.066]$} & {$[0.065]$} & [0.132] & {$[0.128]$} \\
\hline \multirow[t]{2}{*}{$\left.\operatorname{lnFDI}\right|^{k}$} & 0.006 & $0.100^{*}$ & 0.010 & $0.103^{\star \star}$ & $-0.074 * *$ & $-0.124 * *$ & -0.062 & $-0.120^{*}$ \\
\hline & {$[0.044]$} & {$[0.061]$} & {$[0.043]$} & {$[0.051]$} & {$[0.037]$} & {$[0.056]$} & [0.039] & {$[0.065]$} \\
\hline \multirow[t]{2}{*}{$R \& D_{s}{ }^{k}$} & -0.009 & -0.022 & -0.009 & -0.022 & -0.007 & -0.004 & -0.009 & -0.006 \\
\hline & {$[0.017]$} & {$[0.016]$} & {$[0.014]$} & {$[0.015]$} & {$[0.011]$} & {$[0.010]$} & {$[0.012]$} & {$[0.012]$} \\
\hline \multirow[t]{2}{*}{$\ln F D I_{s}{ }^{k}{ }^{*} \ln R \& D_{s}{ }^{k}$} & & $0.017^{*}$ & & $0.017^{*}$ & & 0.016 & & 0.016 \\
\hline & & {$[0.009]$} & & {$[0.010]$} & & {$[0.011]$} & & {$[0.011]$} \\
\hline \multirow[t]{2}{*}{$\ln R \& D^{v}$} & 0.035 & -0.046 & 0.033 & -0.048 & 0.017 & 0.035 & 0.023 & 0.044 \\
\hline & {$[0.046]$} & [0.058] & {$[0.047]$} & {$[0.056]$} & [0.049] & {$[0.054]$} & {$[0.042]$} & {$[0.050]$} \\
\hline \multirow[t]{2}{*}{$\left.\operatorname{lnFDI}\right|_{s}{ }^{k}{ }^{*} \ln R \& D^{v}$} & & $0.502 * *$ & & $0.504^{* *}$ & & -0.15 & & -0.171 \\
\hline & & {$[0.230]$} & & {$[0.201]$} & & {$[0.151]$} & & {$[0.158]$} \\
\hline Dummies & yes & yes & yes & yes & yes & yes & yes & yes \\
\hline Obs & 263 & 263 & 263 & 263 & 372 & 372 & 357 & 357 \\
\hline R-sq & 0.37 & 0.37 & 0.37 & 0.39 & 0.39 & 0.44 & 0.44 & 0.44 \\
\hline Under-id ${ }^{\S}$ & & & $70.0^{* \star *}$ & $71.6^{\star \star \star}$ & & & $56.6^{* * *}$ & $58.8^{* * *}$ \\
\hline Weak-id ${ }^{\S \S}$ & & & 90.6 & 92.7 & & & 64.4 & 67 \\
\hline
\end{tabular}

Standard errors in Brackets; * significant at $10 \%$; **significant at 5\%; *** significant at $1 \% .{ }^{8}$ Anderson canonical correlation LM statistic ${ }^{\S \S}$ Cragg-Donald Wald statistic. Instrument used: average unit value.

Summing up, we find evidence that in HS industries $U V R w$ is positively influenced by technological variables. The estimates confirm the theoretical assumptions that technological spillovers are effective in fostering quality upgrading in CEECs-4 HS industries and that the former are larger the higher the absorptive capacity. The above results, as expected, do not apply to LS industries.

\subsection{Demand for quality and market shares}

We are now able to estimate equation (14) of the theoretical model that underlines the relevance of both price and quality competitiveness in the trends of CEECs-4' market shares with respect to EU-14 partner countries. Given the theoretical assumption, validated by the econometric 
analysis of section 5.2, that quality matters only for trade in advanced products, we perform the estimates only for HS industries.

We regress the growth rates of market shares on the growth rates of relative prices and on a measure of trade partners' "preference for quality". In this respect, as in Hallak (2006 and 2010) and Crinò and Epifani (2010), we posit that the intensity of preference for quality - represented by $\omega$ in equation (14), is a logarithmic function of the importer per-capita income. This amounts to assuming that richer countries spend a larger fraction of their income on goods with a higher quality content. Given the results obtained in the first step, we are able to use the fitted values of $\Delta \ln U V R w_{s}^{k, v}$, obtained from the full OLS estimates (column 2 in Table 2), as the proxy for goods' quality ratio. Consequently, in the estimation of the impact of the preference for quality on market share changes we take into account the technological variables through their impact on the $U V R w .^{16}$

We now denote the fitted values of $U V R w$ as $\Delta \ln \overline{U V R} w_{s}^{k, v}$. We thus build a measure of the preference for quality (the 'Linder term') by interacting each industry's $\Delta \ln \overline{U V R} w_{s}^{k, v}$ with the growth rate of per-capita GDP of the partner country. The above specification accounts for the dynamical perspective of our analysis that focuses on the innovation-driven changes in the pattern of trade. This calls for two differences with respect to Hallak (2010). First, we use the fitted values of $U V R w$ to proxy quality, instead of per-capita income, given our focus on countries that feature a relatively lower per-capita income than EU members', despite the quality level of HS products is comparable to EU's. In addition, since we showed that changes in the $U V R w$ are closely related to the technological catching up of each sector, this variable represents more faithfully the underling dynamical tendencies taking place in the given sector. Secondly, we consider that the intensity of preference for quality may change between the initial and final year. Consequently, the preferencefor-quality term we consider in our estimation of the market shares changes is:

\footnotetext{
${ }^{16}$ The use of the fitted values from the first step estimation has the additional advantage to correct the endogeneity bias of the $U V R w$ coefficient.
} 


$$
\begin{aligned}
& Q D E M w_{s}^{k, v} \equiv \Delta\left(\ln G D P^{v} * \ln \overline{U V R} w_{s}^{k, v}\right)=\ln \overline{U V R} w_{s}^{k, v} * \Delta \ln G D P^{v}+ \\
& +\ln G D P^{v} * \Delta \ln \overline{U V R} w_{s}^{k, v}+\Delta \ln G D P^{v} * \Delta \ln \overline{U V R} w_{s}^{k, v}
\end{aligned}
$$

The first two terms of the RHS are not significant because their impact is captured by the fixed effects; accordingly, we use only the term $\left(\Delta \ln G D P^{v} * \Delta \ln \overline{U V R} w_{s}^{k, v}\right)$ as a measure of the change in preference for quality.

The equation we estimate is the following:

$$
\begin{aligned}
& \Delta \ln M K T s h_{s}^{k, v}=\alpha_{0}+\alpha_{1} \Delta \ln \overline{U V R} w_{s}^{k, v}+\alpha_{2} Q D E M w_{s}^{k, v}+ \\
& +\gamma_{1} D C_{k}+\gamma_{2} D C_{s}+\gamma_{3} D C_{v}+\varepsilon_{s, v}
\end{aligned}
$$

where $M K T s h_{s}^{k, v}$ is the market share of the reporter country $k$ in the partner country $v$.In the estimation $\Delta \ln \overline{U V R} w_{s}^{k, v}$ captures the traditional price effect, ${ }^{17} Q D E M w_{s}^{k, v}$ the preference for quality effect, and $D C_{k}, D C_{s}$ and $D C_{v}$ are dummy variables for reporter countries $k$, sectors $s$ and partners $v$, respectively. In particular, partners' dummies include the impact of foreign GDP growth rate which has to be included as a main effect, being part of the interaction term $Q D E M w_{s}^{k, v}$. All variables of interest are expressed in logs, and therefore log differences represent growth rates between 2000 and 2007. We carry out OLS regression. It is worth noting that, since we consider fixed goods, i.e., only products traded both in 2000 and 2007, market shares' changes with respect to EU competitors measure a modification in the "intensive margin".

The results - reported in Table 3- validate our assumption of a successful competitiveness in "quality-dominated" markets: the estimated coefficients are significant and of the expected sign, i.e., negative for the relative price term $\Delta \ln \overline{U V R} w_{s}^{k, v}$ and positive for the demand for quality term $Q D E M w_{s}^{k, v}$. The estimates are robust to the direct inclusion of technological variables, proving that the effect of technology on market shares operates through the variable used as a proxy for

\footnotetext{
${ }^{17}$ As to the price effect, we use the fitted values of $U V R w$ given that the variable has to be included as a main effect in the regression, being it part of the interacted variable $Q D E M$.
} 
quality. ${ }^{18}$ In conclusion, the empirical evidence highlights that quality competitiveness is a strong determinant of CEECs' market shares changes with respect to high-income EU-14 countries over the period considered.

Table 3 - Determinants of CEECs-4 market shares' changes in EU-14 imports

\begin{tabular}{llll}
\hline \multicolumn{3}{c}{ High-skill industries } \\
\hline$\Delta \ln \overline{U V R} w_{s}^{k, v}$ & $-0.935^{* * *}$ & $-1.097^{* * *}$ & $-1.298^{* * *}$ \\
& {$[0.206]$} & {$[0.203]$} & {$[0.225]$} \\
$Q D E M w_{s}^{k, v}$ & $7.066^{* *}$ & $7.687^{* *}$ & $8.002^{* *}$ \\
& {$[3.281]$} & {$[3.292]$} & {$[3.159]$} \\
$\alpha_{0}$ & 0.203 & -0.004 & -0.314 \\
& {$[0.225]$} & {$[0.250]$} & {$[0.313]$} \\
dummies & $\mathrm{DC}$ & $\mathrm{DC} \mathrm{k}_{\mathrm{v}} \mathrm{DC}$ & $\mathrm{DC} \mathrm{C}_{\mathrm{v}}, \mathrm{DC}_{\mathrm{s},} \mathrm{DC}$ \\
$\mathrm{N}$ & 263 & 263 & 263 \\
$\mathrm{R}$ & 0.150 & 0.179 & 0.276 \\
\hline Robust standard errors in brackets. * significant at $10 \% ; * *$ significant at $5 \% ; * * *$ significant at $1 \%$
\end{tabular}

\section{Concluding remarks}

In the paper we consider the role of vertical innovation in the evolution of competitiveness in trade for emerging market economies undergoing a process of economic integration with technologically advanced countries. We first address the issue from a theoretical point of view, and then provide some empirical evidence of the main theoretical results by considering trade between CEECs and EU. We distinguish between HS industries where firms produce technologically advanced goods, thanks to research activity, and LS industries where firms manufacture traditional products. HS firms compete in "quality dominated" markets and non-price effects stemming from quality differences matter for market penetration, whereas LS firms rely on a standard cost competition. The model shows the role of supply of and demand for quality in shaping the pattern of trade; this turns out to depend, on one side, on the emerging economy's ability to reduce its

\footnotetext{
${ }^{18}$ Results are available upon request.
} 
quality gap with respect to rich competitors, also thanks to knowledge spillovers fuelled by economic integration and, on the other side, on the partner's intensity of quality preference.

Our empirical investigation is carried out with reference to changes in market shares of CEECs products in EU markets over the period 2000-2007. Descriptive evidence suggests that HS firms have engaged successfully in innovation-driven competition in EU markets. We run an econometric analysis in two successive steps. We first test the assumption that $U V R w$ is an adequate measure of quality, showing the existence of a systematic correlation with domestic and foreign technological variables. We then use the estimated $U V R w$ to assess the role of preference for quality in CEECs-4' exports towards EU markets, finding that the increase in HS market shares is significantly correlated to the intensity of quality preference of high-income EU countries. Our estimations definitely support the conclusions obtained in the theoretical model.

\section{References}

Abramovitz, M. 1986. "Catching Up, Forging Ahead, and Falling Behind.” Journal of Economic History 46, no. 2:385-406.

Aiginger, K. 1997. "The use of unit values to discriminate between price and quality competition." Cambridge Journal of Economics 21, no. 5:571-592.

Aturupane, C., S. Djankov and B. Hoekman. 1997. "Determinants of Intra-Industry Trade between East and West Europe." CEPR Discussion Paper, no. 1721, October.

Benkovskis, K., and R. Rimgailaite. 2010. “The Quality and Variety of Exports from New EU Member State: Evidence from Very Disaggregated Data.” Latvijas Banka Working Paper, no. 2.

Bils, M. and P.J. Klenow. 2001. “Quantifying Quality Growth.” American Economic Review 91, no. 4:1006-1030.

Brooks, E. L. 2006. “Why Don't Firms Export More? Product Quality and Colombian Plants.” Journal of Development Economics 80, no. 1:160-178. 
Caporale, G.M., C. Rault, R. Sova and A. Sova. 2009. "Trade Specialisation and Economic Convergence: Evidence from Two Eastern European Countries." DIW Discussion Papers no. 875.

Cavallaro, E., and M. Mulino. 2008. "Vertical Innovation and Catching-Up: Implications of EU Integration for CEECs-5." International Advances in Economic Research 14, no. 3:265-279.

Cavallaro, E., and M. Mulino. 2009a. "Innovation, Competitiveness and Growth: The Case of Central and Eastern European Countries" in H. Marques, E. Soukiazis and P. Cerqueira (eds.) Integration and Globalization. Edward Elgar, Cheltenham, UK.

Cavallaro, E., and M. Mulino. 2009b. "Technological catching up, competitiveness and growth.” Journal of International Trade \& Economic Development 18, no. 4:505-525.

Crinò, R., and P. Epifani. 2010. "Productivity, Product Quality and Export Intensities.” mimeo, Bocconi University, Milan.

Dulleck, U., N. Foster, R. Stehrer and J. Woerz. 2005. "Dimensions of Quality Upgrading. Evidence from CEECs.” Economics of Transition 13, no. 1:51-76.

Esposito, P., and R. Stehrer. 2009. "The Sector Bias of Skill-Biased Technical Change and the Rising Skill Premium in Transition Economies.” Empirica 36, no. 3:351-364.

Fabrizio, S., D. Igan and A. Mody. 2007. “The Dynamics of Product Quality and International Competitiveness." IMF Working Paper no. 97, April.

Flam, H., and E. Helpman. 1987. "Vertical Product Differentiation and North-South Trade." American Economic Review, 77, no. 5:810-822.

Fontagné, L., and M. Freudenberg. 1997. “Intra-Industry Trade: Methodological Issues Reconsidered.” CEPII Working Paper no. 97/02, January.

Greenaway, D., R. Hine, and C. Milner. 1995. "Vertical and Horizontal Intra-Industry Trade: A Cross Country Analysis for the United Kingdom.” Economic Journal 105 no. 433:1505-1518.

Grossman, G.M., and E. Helpman. 1991. Innovation and Growth in the Global Economy. Cambridge MA: MIT Press. 
Hallak, J.C. 2006. "Product Quality and the Direction of Trade." Journal of International Economics 68 no. 1:238-265.

Hallak, J.C. 2010. “A Product-quality view of the Linder Hypothesis.” The Review of Economics and Statistics XCII, no. 3:453-466.

Hallak, J.C., and P.K. Schott. 2011. "Estimating Cross-Country Differences in Product Quality." Quarterly Journal of Economics 126, no. 1:417-474.

Hummels, D., and P.J. Klenow. 2005. "The Variety and Quality of a Nation's Exports.” American Economic Review 95, no. 3:704-723.

Keller, W. 2004. "International Technology Diffusion.” Journal of Economic Literature 42, no. 3:752-782.

Landesmann, M.; S. Leitner; R. Stehrer; and T. Ward. 2009. "Skills and Industrial Competitiveness." WIIW Research Report no. 356.

Léon-Ledesma, M.A. 2005. "Exports, Product Differentiation and Knowledge Spillovers.” Open Economies Review 16, no. 4:363-379.

Linder, S. 1961. An Essay on Trade and Transformation. Stockholm: Almqvist and Wiksell.

Maggi, B., P.C. Padoan and P. Guerrieri. 2009. "A continuous time model of European growth, integration and technology diffusion: The role of distance". Economic modelling 26: 631-40.

Murphy, K., and A. Shleifer. 1997. "Quality and Trade”. Journal of Development Economics 53, no. 1:1-15.

Schott, P. 2004. “Across-Product versus Within-Product Specialization in International Trade.” The Quarterly Journal of Economics 119, no. 2:647-678.

Smulders, S. 2004. "International capital market integration: Implications for convergence, growth and welfare." International Economics and Economic Policy 1, no. 2-3:173-194.

Stokey, N.L. 1991. "The Volume and Composition of Trade Between Rich and Poor Countries." Review of Economic Studies 58, no. 1:63-80. 
van Pottelsberghe de la Potterie, B., and F. Lichtenberg. 2001. "Does Foreign Direct Investment Transfer Technology across Borders?” Review of Economics and Statistics 83, no. 3:490-497.

Verhoogen, E.A. 2008. "Trade, Quality Upgrading, and Wage Inequality in the Mexican Manufacturing Sector." Quarterly Journal of Economics 123, no. 2:489-530.

\section{Appendix - Solution to the consumer's static maximization problems.}

\section{A) Allocation of expenditure for each product across quality levels}

In the first stage of utility maximization each consumer $h$ allocates expenditure within-product quality levels, $\kappa$ and $\kappa^{*}$, by solving the following static problem:

$$
\max _{C_{H(.)}} \sum_{\kappa} q_{H(\kappa)}{ }^{\omega} C_{H(\kappa, n)} \quad \text { for } n=1, \ldots \ldots, N
$$

s.t. $\quad E_{n}^{h}=\sum_{\kappa} P_{H(\kappa, n)} C_{H(\kappa, n)}$

and

$$
\max _{C_{F(.)}} \sum_{\kappa^{*}} q_{F\left(\kappa^{*}\right)} C_{F\left(\kappa^{*}, n^{*}\right)} \quad \text { for } n^{*}=1, \ldots \ldots, N^{*}
$$

s.t. $\quad E_{n^{*}}^{h}=\sum_{\kappa^{*}} P_{F\left(\kappa^{*}, n^{*}\right)} C_{F\left(\kappa^{*}, n^{*}\right)}$

where $E_{n}^{h}$ and $E_{n^{*}}^{h}$ are consumer's expenditures in advanced domestic and foreign industries $n$ and $n^{*}$, respectively, at time $t$, with $\sum_{n} E_{n}^{h}+\sum_{n^{*}} E_{n^{*}}^{h}=\alpha E^{h}$, and where $P_{H(\kappa, n)}$ and $P_{F\left(\kappa^{*}, n^{*}\right)}$ are the prices of the brands $\kappa$ and $\kappa^{*}$, and $\alpha E^{h}$ is consumer's expenditure on advanced products.

For any good $n$, utility maximization implies a positive demand only for the brand $C_{H(\hat{\kappa}, n)}^{h}$ that carries the lowest quality-adjusted price:

$$
\begin{aligned}
& C_{H(\hat{\kappa}, n)}^{h}=\frac{E_{n}}{P_{H(\hat{\kappa}, n))}}, \\
& C_{H(\kappa, n)}^{h}=0 \text { for all vintages } \kappa \neq \hat{\kappa} .
\end{aligned}
$$


where $P_{H(\hat{\kappa}, n)}$ is the price of the brand $\hat{\kappa}$ that carries the lowest quality-adjusted price.

The consumer is thus indifferent between quality vintages $\kappa$ and $\kappa-1$ of any domestic product $n$ if and only if $\frac{P_{H(\kappa, n)}}{P_{H(\kappa-1, n)}}=\gamma^{\omega}$, where $\gamma=\frac{q_{H(\kappa)}}{q_{H(\kappa-1)}}$ is the increase in quality between two successive vintages. Same reasoning applies to choice among quality vintages of any foreign product $n^{*}$.

\section{B) Allocation of expenditure across (state-of-the-art) products}

In the second stage, each consumer optimally allocates expenditure across the $N$ domestic and $N^{*}$ foreign (state-of-the-art) advanced products. The demand function in equation (9) follows from the solution to the following static optimization programme:

$$
\begin{aligned}
\max _{C_{H(. .)}, C_{F(.)}}\left[\sum_{n}\left(\left(q_{H(\hat{\kappa})}\right)^{\omega} C_{H(\hat{\kappa}, n)}\right)^{\sigma_{A}}+\sum_{n^{*}}\left(\left(q_{F\left(\hat{\kappa}^{*}\right)}\right)^{\omega} C_{F\left(\hat{\kappa}^{*}, n^{*}\right)}\right)^{\sigma_{A}}\right]^{\frac{1}{\sigma_{A}}} \\
\text { s.t. } \quad \alpha E^{h}=\sum_{\hat{\kappa}} \sum_{n} P_{H(\hat{\kappa}, n)} C_{H(\hat{\kappa}, n)}+\sum_{\hat{\kappa}^{*}} \sum_{n^{*}} P_{F\left(\hat{\kappa}^{*}, n^{*}\right)} C_{F\left(\hat{\kappa}^{*}, n^{*}\right)}
\end{aligned}
$$

where $C_{F\left(\hat{\kappa}^{*}, n^{*}\right)}$ is the demand of the foreign brand $\hat{\kappa}^{*}$ that carries the lowest quality-adjusted price, and $P_{F\left(\hat{\kappa}^{*}, n^{*}\right)}$ its price. The foreign consumer demand function for any domestic advanced product in equation (14) is obtained by solving an optimization problem analogous to the one above. 